\title{
Expert Consensus on a Canadian Internal Medicine Ultrasound Curriculum
}

By The Western Canadian Internal Medicine Ultrasound Curriculum Committee (Shane Arishenkoff MD, Marcus Blouw MD, Sharon Card MD, John Conly MD, Colin Gebhardt MD, Neil Gibson MD, Ryan Lenz MD, Irene W. Y. Ma MD, Graydon S. Meneilly MD, Leanne Reimche MD, Jeffrey Schaefer MD, Michael Sochocki MD, and Kelly Zarnke MD

\section{About the Authors}

Shane Arishenkoff and Graydon S. Meneilly represent the University of British Columbia; Neil Gibson represents the University of Alberta; John Conly, Ryan Lenz, Irene W. Y. Ma, Leanne Reimche, Jeffrey Schaefer, and Kelly Zarnke represent the University of Calgary; Sharon Card and Colin Gebhardt represent the University of Saskatchewan; and Marcus Blouw and Michael Sochocki represent the University of Manitoba. Correspondence may be directed to ima@ucalgary.ca.

\section{Summary}

Ultrasonography is increasingly used at the bedside. In the absence of an already developed curriculum appropriate for Canadian internal medicine training programs, 13 representatives from internal medicine programs in five Western Canadian provinces met for 2 days to develop and propose a consensus-based internal medicine curriculum for training in the bedside use of ultrasonography in a Canadian health care context. All 13 had had interest or leadership role in those programs. The curriculum's content was based on three overarching principles agreed upon by the group: (1) content should be selected on the basis of clinical or educational need; (2) content should be feasible (i.e., both cognitive and technical components of the curriculum could be reasonably taught and learned in a competency-based manner while minimizing potential risks to patients); and (3) content should be evidence based. A consensusbased curriculum of 16 proposed topics is to be considered for the core internal medicine residency training program (postgraduate year [PGY] 1 to PGY 3), and 22 topics are to be considered for general internal medicine subspecialty training programs (PGY 4 to PGY 5).

\section{Résumé}

L'échographie est de plus en plus utilisée dans les soins aux patients. En l'absence d'un cursus adéquat en échographie dans les programmes canadiens de formation à la médecine interne, treize représentants ayant un intérêt ou jouant un rôle de leadership dans ces programmes dans chacune des cinq provinces de l'Ouest se sont rencontrés pendant deux jours afin d'élaborer et de proposer un cursus consensuel en échographie pour la formation des internistes dans le contexte des soins de santé au Canada. Le groupe de travail s'est donné trois grands principes pour établir le contenu du programme : 1) il doit répondre à des besoins cliniques ou pédagogiques; 2 ) il doit être possible de le transmettre (ses éléments cognitifs et techniques peuvent raisonnablement être enseignés et appris dans le cadre d'un enseignement axé sur les compétences, avec un risque potentiel minime pour les patients); 3) il doit être basé sur des données probantes. Nous présentons ici un cursus consensuel comptant 16 propositions à intégrer dans le tronc commun du programme de formation des résidents en médecine interne (R1 à R3) et 22 propositions pour les programmes de formation en sous-spécialité de médecine interne générale (R4 et R5). 


\section{Keywords}

bedside ultrasound; consensus, curriculum content; evidencebased; internal medicine program

$\mathrm{O}$ ver the past decade, bedside ultrasound has been increasingly used by nonimaging specialists, including emergency physicians, obstetricians, and critical care specialists. Ultrasonography can be used as a preclinical tool to improve the understanding of anatomy, physiology, and pathology. Alternatively, it can be used as a clinical tool in making diagnoses at the bedside. ${ }^{1}$ For example, as a preclinical or educational tool, ultrasonography may help learners improve their physical examination techniques (such as those for examining the liver), ${ }^{2}$ and it may be used clinically as a diagnostic tool (e.g., for ruling out pneumothoraces). ${ }^{3}$ This increasing recognition of the role of point-of-care ultrasound at the bedside, as well as its role as a standard of care in assisting procedural skills such as central venous catheterization, highlights the relevance of clinical ultrasonography to internal medicine training and practice. ${ }^{4}$ However, proper training in its use is necessary. ${ }^{5}$ It is increasingly difficult to ignore the need for a defined internal medicine curriculum in regard to what ultrasonographic skills are important for delivering effective care to our patients. At a minimum, postgraduate training programs need to meet the objectives of training put forth by their accrediting bodies (e.g., the Royal College of Physicians and Surgeons of Canada). These typically include competency in placing central venous catheters and in performing a variety of diagnostic and therapeutic bedside procedures. For a number of these procedures, there is accumulating evidence that supports the use of ultrasound guidance for improving procedural safety. ${ }^{6-10}$ Programs that teach these procedures should implement appropriate training in, and assessment of, the use of ultrasound guidance. Further applications of ultrasound may include its use in diagnostic assessments $^{11}$ and as an educational tool (e.g., the use of ultrasound to provide visual feedback to enhance physical examination skills or to increase the understanding and knowledge of physiology and anatomy). ${ }^{12,13}$

What to include in an ultrasonography curriculum appropriate for training in internal medicine has not yet been defined. There are a number of competing interests and demands, including the improvement of patient safety and the need to prepare residents for continuing training in subspecialties that require bedside ultrasound and an understanding of its uses and limitations. Practical considerations include the ability of existing practicing and teaching faculty to acquire, deploy, and teach bedside ultrasound skills; budgetary concerns; patient privacy issues regarding the storage of images; and availability of time to learn ultrasonographic skills within an already full internal medicine educational curriculum. A frequent and important concern among educators is the potential for eager but naive adopters of the technology to use novice skills beyond the intended scope of such skills, resulting in harm to patients. ${ }^{14}$ Therefore, educators designing a curriculum must be mindful of potential risks and benefits, educational values, and unintended consequences.

In the absence of any already developed curriculum appropriate for Canadian internal medicine training programs, we sought to develop and propose a consensus-based internal medicine curriculum for bedside ultrasound use in the Canadian health care context.

\section{Methods}

Internal medicine program representatives with an interest or leadership role in each of the four Western Canadian provinces (British Columbia, Alberta, Saskatchewan, and Manitoba) were identified by their respective programs and invited to partake in a 2-day meeting held at the University of Calgary on June 10-11, 2013. Each invited member had previous training or experiential point-of-care ultrasonography skills, educational expertise, and/or a leadership role in his or her university in advancing education in the use of ultrasonography in internal medicine. Although individual members of the working group have leadership roles locally, nationally, and internationally, this document reflects a consensus of individual opinions and is not intended to reflect the leadership groups to which the individuals belong.

Prior to the meeting, existing guidelines for ultrasonography practice and a training curriculum in emergency and critical care medicine were circulated among the participants. These guidelines covered a variety of topics, such as standards for ultrasound equipment, examination-specific guidelines, the safe use of ultrasound, ${ }^{15}$ the use of ultrasound in procedures, ${ }^{16,17}$ and training and practice standards. ${ }^{18-23}$

On the first day of the meeting, participants discussed and agreed upon the overarching principles by which curriculum content would be selected. In the first round of discussion, a comprehensive list of candidate topics was created on the basis of the experience, knowledge, and interests of the attendees. The entire group was then divided at random into three working groups; each working group discussed and evaluated the proposed candidate topics. A preliminary discussion was held on whether a topic needed to be, should be, or could be included in the internal medicine curriculum, or whether it should not or could not be included in the curriculum. On the basis of the group response to candidate topics, each topic was searched on 
Table 1. Results of First Round of Discussion by 13 Participants on 38 Topics Considered for the Canadian Internal Medicine Ultrasound Curriculum

\begin{tabular}{|c|c|c|c|c|}
\hline Topic No. & Category & Potential Topic & $\begin{array}{c}\text { Votes for Inclusion } \\
(\%)\end{array}$ & $\begin{array}{c}\text { Consensus* for } \\
\text { Further Consideration }\end{array}$ \\
\hline 1 & Volume status & Internal jugular vein height & $13(100)$ & Yes \\
\hline 2 & Volume status & Inferior vena cava measurement & $12(92)$ & Yes \\
\hline 3 & Fluid collections & Pleural & $13(100)$ & Yes \\
\hline 4 & Fluid collections & Ascites & $13(100)$ & Yes \\
\hline 5 & Fluid collections & Pericardial & $13(100)$ & Yes \\
\hline 6 & Renal & Hydronephrosis & $8(62)$ & No \\
\hline 7 & Cardiac & Left ventricular function (gross) & $13(100)$ & Yes \\
\hline 8 & Cardiac & Right ventricular function (gross) & $12(92)$ & Yes \\
\hline$\underline{9}$ & Liver/spleen & Span & $12(92)$ & Yes \\
\hline 10 & Head and neck & Thyroid & $10(77)$ & No \\
\hline 11 & Pulmonary & Pulmonary edema & $12(92)$ & Yes \\
\hline 12 & Pulmonary & Consolidation & $10(77)$ & No \\
\hline 13 & Pulmonary & Pneumothorax & $13(92)$ & Yes \\
\hline 14 & Soft tissue & Abscess/cellulitis & $11(85)$ & Yes \\
\hline 15 & Soft tissue & Joint effusion & $10(77)$ & No \\
\hline 16 & Ophthalmic & Retinal & $0(0)$ & No \\
\hline 17 & Ophthalmic & Intracranial pressure & $2(15)$ & No \\
\hline 18 & Vascular & Aortic dissection & $0(0)$ & No \\
\hline 19 & Vascular & Abdominal aortic diameter & $10(77)$ & No \\
\hline 20 & Vascular & Deep vein thrombosis & $2(15)$ & No \\
\hline 21 & Lymphadenopathy & Lymphadenopathy & $3(23)$ & No \\
\hline 22 & Genitourinary & Bladder & $11(77)$ & Yes \\
\hline 23 & Biliary tree & Cholelithiasis & $2(15)$ & No \\
\hline 24 & Biliary tree & Common bile duct size & $1(8)$ & No \\
\hline 25 & Minors & Fetal & $0(0)$ & No \\
\hline 26 & Minors & Children aged $<16 \mathrm{yr}$ & $0(0)$ & No \\
\hline 27 & Procedures & Central venous catheterization - internal jugular vein & $13(100)$ & Yes \\
\hline 28 & Procedures & Central venous catheterization - subclavian vein & $10(77)$ & No \\
\hline 29 & Procedures & Central venous catheterization - femoral vein & $13(100)$ & Yes \\
\hline 30 & Procedures & PICC & $12(92)$ & Yes \\
\hline 31 & Procedures & Arterial line insertion & $12(92)$ & Yes \\
\hline 32 & Procedures & Peripheral intravenous access & $13(100)$ & Yes \\
\hline 33 & Procedures & Thoracentesis & $13(100)$ & Yes \\
\hline 34 & Procedures & Paracentesis & $13(100)$ & Yes \\
\hline 35 & Procedures & Lumbar puncture & $10(77)$ & No \\
\hline 36 & Procedures & Joint aspiration & $12(92)$ & Yes \\
\hline 37 & Procedures & Abscess aspirate sampling & $13(100)$ & Yes \\
\hline 38 & Procedures & Abscess incision and drainage & $13(100)$ & Yes \\
\hline
\end{tabular}

PICC = peripherally inserted central catheter.

${ }^{*}>80 \%$ agreement.

MEDLINE with the search terms "ultrasound," "ultrason\$," and "point of care," as well as with terms related to the topic. Evidence on each candidate topic was then presented again to all participants.

On the second day, a modified Delphi technique was used to obtain a consensus on the content of a curriculum for internal medicine residency training programs..$^{24}$ In a blinded fashion, participants voted for inclusion versus exclusion of content in the curriculum. Participants were also asked to indicate if the specific topic should be used for teaching physical examination, making a clinical diagnosis, or guiding procedures. Additional rounds of votes and discussion were repeated in an unblinded fashion until participants reached a consensus ( $\geq 80 \%$ agreement) on the topics chosen for inclusion. The entire group then voted on these topics in an unblinded fashion on their appropriateness for inclusion in the core internal medicine program (by the end 


\section{Table 2. Final Consensus of 13 Participants on 22 Topics Proposed for Inclusion in Provisional Internal Medicine Curriculum}

\begin{tabular}{|c|c|c|c|c|}
\hline Topic & $\begin{array}{c}\text { Votes for Inclusion } \\
\text { in Core IM Curriculum } \\
(\%)\end{array}$ & $\begin{array}{l}\text { Consensus }^{\dagger} \text { to } \\
\text { Include in Core } \\
\text { IM Curriculum }\end{array}$ & $\begin{array}{l}\text { Votes for Inclusion } \\
\text { in GIM Subspecialty } \\
\text { Curriculum (\%) }\end{array}$ & $\begin{array}{c}\text { Consensus }^{\dagger} \text { to } \\
\text { Include in GIM } \\
\text { Subspecialty Curriculum }\end{array}$ \\
\hline Internal jugular vein height & $13(100)$ & Yes & $13(100)$ & Yes \\
\hline Inferior vena cava measurement & $12(92)$ & Yes & $13(100)$ & Yes \\
\hline Pleural effusion & $13(100)$ & Yes & $13(100)$ & Yes \\
\hline Pneumothorax & $13(100)$ & Yes & $13(100)$ & Yes \\
\hline Liver and spleen span & $13(100)$ & Yes & $13(100)$ & Yes \\
\hline Ascites & $13(100)$ & Yes & $13(100)$ & Yes \\
\hline Bladder & $12(92)$ & Yes & $13(100)$ & Yes \\
\hline Abscess/cellulitis & $12(92)$ & Yes & $13(100)$ & Yes \\
\hline $\begin{array}{l}\text { Central venous catheterization } \\
\text { - internal jugular vein }\end{array}$ & $13(100)$ & Yes & $13(100)$ & Yes \\
\hline $\begin{array}{l}\text { Central venous catheterization } \\
\text { - femoral vein }\end{array}$ & $13(100)$ & Yes & $13(100)$ & Yes \\
\hline Arterial line insertion & $13(100)$ & Yes & $13(100)$ & Yes \\
\hline Peripheral intravenous access & $13(100)$ & Yes & $13(100)$ & Yes \\
\hline Thoracentesis & $13(100)$ & Yes & $13(100)$ & Yes \\
\hline Paracentesis & $13(100)$ & Yes & $13(100)$ & Yes \\
\hline$\underline{\text { Joint aspiration }}$ & $11(85)$ & Yes & $13(100)$ & Yes \\
\hline Abscess aspirate sampling & $13(100)$ & Yes & $13(100)$ & Yes \\
\hline Abscess incision and drainage & $9(69)$ & No & $13(100)$ & Yes \\
\hline$\underline{\text { PICC }}$ & $5(38)$ & No & $13(100)$ & Yes \\
\hline Pulmonary edema & 0 & No & $12(92)$ & Yes \\
\hline Left ventricular function (gross) & $6(46)$ & No & $13(100)$ & Yes \\
\hline Right ventricular function (gross) & $4(31)$ & No & $13(100)$ & Yes \\
\hline Pericardial effusion & $7(54)$ & No & $13(100)$ & Yes \\
\hline
\end{tabular}

$\mathrm{IM}=$ internal medicine; $\mathrm{GIM}=$ general internal medicine; $\mathrm{PICC}=$ peripherally inserted central catheter.

*Core internal medicine (PGY 1 to PGY 3) or internal medicine/general internal medicine subspecialty (PGY 4 to PGY 5).

of postgraduate year 3 [PGY 3]) and for internal medicine or general internal medicine subspecialty training (at the end of PGY 4 or PGY 5).

\section{Results}

Thirteen individuals participated in the process: two from the University of British Columbia, one from the University of Alberta, six from the University of Calgary, two from the University of Saskatchewan, and two from the University of Manitoba. The internal medicine specialties that were represented included general internal medicine, critical care medicine, infectious disease, nephrology, respirology, and geriatrics. Participants included one current and one former chair of an internal medicine department, one core residency program director, one former program director for PGY 4 and PGY 5 trainees going into general internal medicine (GIM) practice, one GIM division head, five faculty/departmental leaders in ultrasonography training, and two postgraduate trainees in their final 2 years of subspecialty training.

Three principles of curriculum content were agreed upon by the group: (1) content should be selected on the basis of clinical or educational need; (2) content should be feasible (i.e., both cognitive and technical components of the curriculum content can be reasonably taught and learned in a competency-based manner while minimizing potential risks to patients); and (3) content should be evidence based (showing evidence of educational utility and/or improved outcomes).

The group considered 38 topics (Table 1) and selected 22 for further consideration. The group's members unanimously felt that fetal scans on pregnant patients and non-medically indicated scans on children (such as those done simply for training purposes) should not be performed by trainees. Although ultrasound is generally considered to be safe, sound waves do pose concerns about thermal and nonthermal safety. ${ }^{25,26}$ As such, all users are required to adhere to the "as low as reasonably achievable" (ALARA) principle..$^{25}$ The potential bioeffects are of 
particular concern in high-attenuation tissues such as fetal and growing bones. ${ }^{27,28}$ As a result, Health Canada, for non-medical reasons, does not recommend ultrasound for obstetrical use. ${ }^{26}$ Other topics were rejected because of the potential difficulty in teaching and learning them, the potential medico-legal risk, the low likelihood that an acquired skill would lead to changes in management, and the possibility of their being beyond an internist's scope of practice.

Of the 22 included topics, 16 were felt to be potentially suitable for inclusion into a core internal medicine training program (Table 2). Three Delphi rounds were conducted to reach a consensus. These 16 topics included measurement of the height of the internal jugular vein, ${ }^{29,30}$ inferior vena cava measurement, ${ }^{31,32}$ pleural effusion and thoracentesis, ${ }^{8,33,34}$ central line insertion and pneumothorax, ${ }^{3,6,7,35,36}$ liver and spleen examination, ${ }^{2,37}$ ascites and paracentesis, ${ }^{9,38}$ the bladder, ${ }^{14,39,40}$ cellulitis/abscess/aspirates, ${ }^{41,42}$ arterial line insertion, ${ }^{43}$ peripheral intravenous access, ${ }^{44,45}$ and joint aspiration. ${ }^{10}$ Although the evidence for the role of ultrasound in establishing peripheral intravenous access in adults is not as consistent as that in pediatric patients, ${ }^{46}$ the group felt that learning this skill is unlikely to be harmful and may improve the care of patients.

All 22 topics were deemed potentially suitable for a GIM subspecialty curriculum. The additional topics included abscess incision and drainage, ${ }^{41,42}$ peripherally inserted central catheters, ${ }^{16}$ pulmonary edema, ${ }^{47}$ and focused and limited cardiac examination. ${ }^{48-50}$

\section{Discussion}

This is the first consensus-based report on potentially appropriate curriculum content for inclusion into Canadian internal medicine training programs that is mindful of educational, patient safety, and evidence-based principles. Our committee recommends that the 16 proposed topics should be considered for the core internal medicine residency training program (PGY-1 to PGY-3) and that 22 topics be considered for training programs in the general internal medicine subspecialty. Fetal scans on pregnant women and scans on children should not be performed by trainees.

Our report has a number of limitations. First, it is based on expert opinion-based consensus and preliminary evidence only; we did not conduct a comprehensive systematic review using multiple databases on each of the candidate topics. Second, our first meeting was limited in scope, in that our group's members represented only the Western provinces; we did not intend to be exclusive, but owing to practical and feasibility issues, we began with a smaller regional group of centres. Third, although we aimed to adhere to educational, patient safety, and evidence- based principles, the contribution of any curriculum to overall patient safety must ultimately be mindful of content, modes of curriculum delivery, assessment, and program evaluation. Our report does not specify the approach to the curriculum's delivery and implementation (e.g., who teaches, how teaching is done, and the exact content of the curriculum within a topic); consequently, each centre's experience will vary. Fourth, the proposed topics are intended only to be a starting point for curriculum design and should not be followed in a prescriptive manner. Last, we did not address device technology and its affordability or availability. Individual members of the working group have varied experiences with different types of ultrasound devices, but addressing which specific device functionalities training programs should provide is currently beyond the scope of the working group.

\section{Future Directions}

At its next meeting, the group intends to share further institutional experiences, discuss teaching resources and continuing professional development workshops for faculties, and set definitions of minimal competence for select skills. Further, the group plans to discuss potential research ideas that will assist the delivery of further evidence-based medical education in the use of ultrasonography in internal medicine.

\section{Acknowledgements}

We wish to thank Maureen Sorensen, Lori Miller, and Deb Hewko for their assistance with our first meeting. The participants also wish to thank the W21C (Ward of the 21st Century), the University of Calgary, and the University of Calgary's Division of General Internal Medicine for hosting the meeting.

\section{References}

1. Baltarowich $\mathrm{OH}$, Di Salvo DN, Scoutt LM, et al. National ultrasound curriculum for medical students. Ultrasound 2014;30:13-9.

2. Barloon TJ, Brown BP, Abu-Yousef MM, et al. Teaching physical examination of the adult liver with use of real-time sonography. Acad Radiol 1998;5:1013.

3. Lichtenstein DA, Menu Y. A bedside ultrasound sign ruling out pneumothorax in the critically ill: lung sliding. Chest 1995;108:1345-8.

4. Feller-Kopman DMD. Ultrasound-guided central venous catheter placement: the new standard of care? Crit Care Med 2005;33:1875-7.

5. American College of Surgeons. Statement on recommendations for uniform use of real-time ultrasound guidance for placement of central venous catheters. Chicago (IL): The College, 2011; http://www.facs.org/fellows_info/statements/st-60.html. Accessed May 12, 2014.

6. Hind D, Calvert N, McWilliams R, et al. Ultrasonic locating devices for central venous cannulation: meta-analysis. BMJ 2003;327:361.

7. Mehta N, Valesky WW, Guy A, Sinert R. Systematic review: is real-time ultrasonic-guided central line placement by ED physicians more successful 
than the traditional landmark approach? Emerg Med J 2013;30:355-9.

8. Gordon CE, Feller-Kopman D, Balk EM, Smetana GW. Pneumothorax following thoracentesis: a systematic review and meta-analysis. Arch Intern Med 2010;170:332-9.

9. Patel PA, Ernst FR, Gunnarsson CL. Evaluation of hospital complications and costs associated with using ultrasound guidance during abdominal paracentesis procedures. J Med Econ 2012;15:1-7.

10. Sibbitt W, Kettwich L, Band P, et al. Does ultrasound guidance improve the outcomes of arthrocentesis and corticosteroid injection of the knee? Scand J Rheumatol 2012;41:66-72.

11. Moore CL, Copel JA. Point-of-care ultrasonography. New Engl J Med 2011;364:749-57.

12. Solomon SD, Saldana F. Point-of-care ultrasound in medical education - stop listening and look. N Engl J Med 2014;370:1083-5.

13. Hammoudi N, Arangalage D, Boubrit L, et al. Ultrasound-based teaching of cardiac anatomy and physiology to undergraduate medical students. Arch Cardiovasc Dis 2013;106:487-91.

14. Ma I, Wishart I, Kaminska M, et al. Medical educators' perspectives of teaching physical examinations using ultrasonography at the undergraduate level. Can Med Educ J 2013;4:e59-68.

15. United Kingdom Association of Sonographers. Guidelines for professional working standards. Ultrasound practice. United Kingdom Association of Sonographers; 2008.

16. AIUM Practice guideline for the use of ultrasound to guide vascular access procedures. Laurel (MD): American Institute of Ultrasound in Medicine; 2012.

17. Moureau N, Lamperti M, Kelly LJ, et al. Evidence-based consensus on the insertion of central venous access devices: definition of minimal requirements for training. Br J Anaesth 2013;110:347-56.

18. World Health Organization Study Group. Training in diagnostic ultrasound: essentials, principles and standards: report of a WHO study group. Geneva: World Health Organization, 1998.

19. Mayo PH, Beaulieu Y, Doelken P, et al. American College of Chest Physicians/La Société de Réanimation de Langue Française statement on competence in critical care ultrasonography. Chest 2009;135:1050-60.

20. Tolsgaard MG, Todsen T, Sorensen JL, et al. International multispecialty consensus on how to evaluate ultrasound competence: a Delphi consensus survey. PloS one 2013;8:e57687.

21. Expert Round Table on Ultrasound in ICU. International expert statement on training standards for critical care ultrasonography. Intensive Care Med 2011;37:1077-83.

22. American College of Emergency Physicians. Policy statement. Emergency ultrasound guidelines. 2009. Irving (TX): The College, 2009; http://www.acep.org/policystatements/. Accessed May 12, 2014.

23. Bennett S. Training guidelines for ultrasound: worldwide trends. Best Pract Res Clin Anaesthesiol 2009;23:363-73.

24. Clayton MJ. Delphi: a technique to harness expert opinion for critical decision-making tasks in education. Educ Psychol 1997;17:373-86.

25. American Institute of Ultrasound in Medicine. Medical ultrasound safety. 2nd ed. Laurel (MD): The Institute, 2009.

26. Health Canada. Guidelines for the safe use of diagnostic ultrasound. In: Minister of Public Works and Government Services Canada, 2001.

27. Rumack CM, Wilson SR, Charboneau JW, Levine D. Diagnostic ultrasound. 4th ed. Philadelphia: Mosby, 2011.

28. Safety Group of the British Medical Ultrasound Society. Guidelines for the safe use of diagnostic ultrasound equipment. Ultrasound 2010;18:52-9.

29. Keller AS, Melamed R, Malinchoc M, et al. Diagnostic accuracy of a simple ultrasound measurement to estimate central venous pressure in spontaneously breathing, critically ill patients. J Hosp Med 2009;4:350-5.

30. Donahue SP, Wood JP, Patel BM, Quinn JV. Correlation of sonographic measurements of the internal jugular vein with central venous pressure. Am J
Emerg Med 2009;27:851-5.

31. Muller L, Bobbia X, Toumi M, et al. Respiratory variations of inferior vena cava diameter to predict fluid responsiveness in spontaneously breathing patients with acute circulatory failure: need for a cautious use. Crit Care 2012;16:R188.

32. Lanspa MJ, Grissom CK, Hirshberg EL, et al. Applying dynamic parameters to predict hemodynamic response to volume expansion in spontaneously breathing patients with septic shock. Shock 2013;39:155-60.

33. Grogan DR, Irwin RS, Channick R, et al. Complications associated with thoracentesis: a prospective, randomized study comparing three different methods. Arch Intern Med 1990;150:873-7.

34. Jones PW, Moyers JP, Rogers JT, et al. Ultrasound-guided thoracentesis. Chest 2003;123:418-23.

35. Blaivas M, Lyon M, Duggal S. A prospective comparison of supine chest radiography and bedside ultrasound for the diagnosis of traumatic pneumothorax. Acad Emerg Med 2005;12:844-9.

36. Hilty WM, Hudson PA, Levitt MA, Hall JB. Real-time ultrasound-guided femoral vein catheterization during cardiopulmonary resuscitation. Ann Emerg Med 1997;29:331-7.

37. Angtuaco TL, Hopkins RH, DuBose TJ, et al. Sonographic physical diagnosis 101: teaching senior medical students basic ultrasound scanning skills using a compact ultrasound system. Ultrasound Q 2007;23:157-60.

38. Nazeer SR, Dewbre H, Miller AH. Ultrasound-assisted paracentesis performed by emergency physicians vs the traditional technique: a prospective, randomized study. Am J Emerg Med 2005;23:363-7.

39. Akhtar S, Theodoro D, Gaspari R, et al. Resident training in emergency ultrasound: consensus recommendations from the 2008 Council of Emergency Medicine Residency Directors Conference. Acad Emerg Med 2009;16:S32-6.

40. Bonnard P, Boutouaba S, Diakhate I, et al. Learning curve of vesico-urinary ultrasonography in Schistosoma haematobium infection with WHO practical guide: a "simple to learn" examination. Am J Trop Med Hyg 2011;85:1071-4.

41. Tayal VS, Hasan N, Norton HJ, Tomaszewski CA. The effect of soft-tissue ultrasound on the management of cellulitis in the emergency department. Acad Emerg Med 2006;13:384-8.

42. Squire BT, Fox JC, Anderson C. ABSCESS: applied bedside sonography for convenient evaluation of superficial soft tissue infections. Acad Emerg Med 2005;12:601-6.

43. Shiver S, Blaivas M, Lyon M. A prospective comparison of ultrasound-guided and blindly placed radial arterial catheters. Acad Emerg Med 2006;13:12759.

44. Bauman M, Braude D, Crandall C. Ultrasound-guidance vs. standard technique in difficult vascular access patients by ED technicians. Am J Emerg Med 2009;27:135-40.

45. Costantino TG, Parikh AK, Satz WA, Fojtik JP. Ultrasonography-guided peripheral intravenous access versus traditional approaches in patients with difficult intravenous access. Ann Emerg Med 2005;46:456-61.

46. Stein J, George B, River G, et al. Ultrasonographically guided peripheral intravenous cannulation in emergency department patients with difficult intravenous access: a randomized trial. Ann Emerg Med 2009;54:33-40.

47. Volpicelli G, Elbarbary M, Blaivas M, et al. International evidence-based recommendations for point-of-care lung ultrasound. Intensive Care Med 2012;38:577-91.

48. Kobal SL, Atar S, Siegel RJ. Hand-carried ultrasound improves the bedside cardiovascular examination. Chest 2004;126:693-701.

49. Hellmann DB, Whiting-O'Keefe Q, Shapiro EP, et al. The rate at which residents learn to use hand-held echocardiography at the bedside. Am J Med 2005;118:1010-8.

50. Decara JM, Kirkpatrick JN, Spencer KT, et al. Use of hand-carried ultrasound devices to augment the accuracy of medical student bedside cardiac diagnoses. J Am Soc Echocardiogr 2005;18:257-63. 